\title{
REVIEW
}

\section{Adenoid cystic carcinoma. An indolent but aggressive tumour. Part A: from aetiopathogenesis to diagnosis}

\author{
Carcinoma adenoide cistico. Un tumore indolente ma aggressivo. \\ Parte A: dalla eziopatogenesi alla diagnosi \\ Giulio Cantù \\ Former Director of Otorhinolaryngology and Cranio-Maxillo-Facial Unit, Fondazione I.R.C.C.S. Istituto Nazionale dei Tumori, Milano, Italy
}

\begin{abstract}
SUMMARY
Adenoid cystic carcinoma (ACC) is a relatively rare tumour of the minor and major salivary glands. It is uncommon in the parotid gland while it is much more frequent in the submandibular gland and in minor salivary and mucinous glands (oral cavity, oropharynx, and paranasal sinuses). ACC may also arise in secretory glands located in other tissues, such as in the tracheobronchial tree, oesophagus, breast, lungs, prostate, uterine cervix, lachrymal and Bartholin's glands, and skin. The natural history of ACC is characterised by an indolent growth rate, a relatively low probability of regional lymph node metastases and a high likelihood of haematogenous dissemination. ACC has been traditionally subdivided into three histological groups (cribriform, tubular, and solid) based on solid components of the tumour. Some studies have shown that tumours with a solid growth component have a rapid fatal course, compared to tumours without a solid growth component, but other studies have failed to correlate growth patterns with clinical course. The purpose of this review is to analyse the very large number of studies (sometimes contradictory) on ACC. In this first part, the aetiology, epidemiology, histopathology, clinical behaviour and diagnostic workup are examined.
\end{abstract}

KEY WORDS: adenoid cystic carcinoma, salivary gland tumours, head and neck cancer, prognostic factors

\section{RIASSUNTO}

Il carcinoma adenoide cistico (ACC) è un tumore relativamente raro ad origine dalle ghiandole salivari minori e maggiori. È poco frequente nella parotide mentre lo ̀̀ molto di più nella ghiandola sottomandibolare, nelle ghiandole salivari minori e in quelle mucinose del cavo orale, orofaringe e seni paranasali. Esso può anche insorgere nelle ghiandole secretrici localizzate in altri tessuti come l'albero tracheo-bronchiale, l'esofago, la mammella, il polmone, la prostata, la cervice uterina, la cute, le ghiandole lacrimali e quelle del Bartolini. La sua storia naturale è caratterizzata da una lenta crescita, da rare metastasi linfonodali e da frequenti metastasi a distanza. Dal punto di vista istologico esso è stato tradizionalmente suddiviso in tre forme (cribriforme, tubulare e solido). Alcuni studi hanno dimostrato che $i$ tumori con una prevalente componente solida hanno una prognosi peggiore rispetto a quelli con prevalente componente cribriforme o tubulare ma altri studi hanno contestato questa affermazione. Il proposito di questa review è quello di analizzare il grande numero di pubblicazioni (talvolta contraddittorie) sul carcinoma adenoide cistico. In questa prima parte saranno discusse l'eziologia, l'epidemiologia, l'istopatologia, la presentazione clinica e l'iter diagnostico.

PAROLE CHIAVE: carcinoma adenoide cistico, tumori ghiandole salivari, carcinoma testa e collo, fattori prognostici

\section{Introduction}

Adenoid cystic carcinoma (ACC) represents 3-5\% of head and neck malignancies ${ }^{1}$ and $5-15 \%$ of sinonasal malignancies. It is characterised by an indolent but aggressive clinical course, the presence of early perineural invasion, fre-
Received: January 12, 2021

Accepted: May 3, 2021

\section{Correspondence}

Giulio Cantù

via Milano 36, 20846 Macherio (MB), Italy

E-mail: gcantu43@gmail.com

Funding

None.

Conflict of interest

The Author declares no conflict of interest.

How to cite this article: Cantù G. Adenoid cystic carcinoma. An indolent but aggressive tumour. Part A: from aetiopathogenesis to diagnosis. Acta Otorhinolaryngol Ital 2021;41:206-214. https:// doi.org/10.14639/0392-100X-N1379

(c) Società Italiana di Otorinolaringoiatria e Chirurgia Cervico-Facciale

\section{(c) (1) $(9)$}

This is an open access article distributed in accordance with the CC-BY-NC-ND (Creative Commons Attribution-NonCommercial-NoDerivatives 4.0 International) license. The article can be used by giving appropriate credit and mentioning the license, but only for non-commercial purposes and only in the original version. For further information: https:// creativecommons.org/licenses/by-nc-nd/4.0/deed.en 
quent local recurrence and a high rate of delayed distant metastasis. This tumour was pointed out as a specific entity in the middle $19^{\text {th }}$ century. Stell PM, in a fascinating "History of surgery of the upper jaw" ${ }^{2}$, wrote: "It is often said that adenoid cystic carcinoma was first described by Billroth in 1859 by the term Zylindrome. This is untrue: the tumour was first described by two Frenchmen, Robin \& Laboulbene, as "tumeur heteradenique", in 1853". However, the histopathologic term for ACC was "cylindroma" for many years, based on the histologic appearance of cylinders of epithelial/secretory cells and a hyaline stroma. Spiro and Huvos ${ }^{3}$ wrote that only in 1953 Foot and Frazell ${ }^{4}$ classified the tumour as an adenocarcinoma, coining the term "adenoid cystic carcinoma". The aim of the first part of this review is to provide an update on the current understanding of aetiology, epidemiology, clinical behaviour, pathology, molecular biology and diagnostic work up of ACC. Treatment and prognosis will be analysed in the second part.

\section{Aetiology}

Few studies to date have examined the possible aetiologic factors conclusively associated with the development of salivary gland cancers. Some factors have been implicated as potential causes for these malignancies, especially exposure to ionising radiation (atomic bomb survivors ${ }^{5}$ and patients treated with radiotherapy for a previous tumour ${ }^{6}$, especially childhood cancer). Three population-based casecontrol studies reported elevated odds ratios among agricultural $^{7}$, nickel and rubber ${ }^{8}$ workers, women employed as hairdressers and those working in beauty shops ${ }^{9}$. HornRoss et al. ${ }^{10}$ made a population-based case-control study and found that vitamin $\mathrm{C}$ intake of $>200 \mathrm{mg} /$ day compared with $\leq 100 \mathrm{mg} /$ day was associated with a $60 \%$ decrease in salivary gland cancer risk, and intake of fibres from bean sources $>1.4 \mathrm{~g} /$ day was associated with a $51 \%$ decrease in risk.

With regards to previous tumours, Spitz et al. ${ }^{7}$, found that the most common site for previous malignancy among their patients with salivary gland cancer was the skin (odds ratio 11.41). However, the authors specified that many of their patients with previous skin cancer underwent radiotherapy. Falchook et al. ${ }^{11}$ evaluated the incidence of salivary gland cancer among patients with a history of cancer, and explored the potential significance of index breast cancer on the subsequent risk of salivary gland malignancy. They found that in patients with a previous cancer diagnosis, the risk of subsequent salivary gland malignant tumour was greater in women than men. However, women with previous breast cancer were not more likely to develop salivary gland cancer than women with other previous malignan- cies. On the contrary, analysis of different cancer registries has shown that women diagnosed with breast cancer have an increased incidence of subsequent salivary gland cancer $^{12}$. However, the analysis of the possible aetiologic factors associated with ACC is complicated by the fact that some epidemiologic studies report salivary gland cancers without subdivision according to histologic type ${ }^{9}$.

Although smoking and alcohol drinking are two wellknown strong carcinogens in many tumours, few studies have examined the effect of these factors on the risk of ACC. In a case-control study, Sawabe et al. ${ }^{13}$ investigated the association between smoking and major salivary gland cancers and found that smoking was associated with a significantly increased risk of salivary gland tumours overall, especially in heavy smokers compared with neversmokers. When stratified by histological subtype, no impact of smoking was observed among patients with mucoepidermoid carcinoma (MEC). In contrast, smoking demonstrated a significantly increased risk of cancers other than MEC, specifically for adenocarcinoma. Although not significant, the odds ratios for smoking among patients with ACC were above unity. The authors also pointed out 7 previous studies on the same topic, with 4 indicating a positive association $8,9,14,16$ and 3 demonstrating no appreciable association $7,15,17$. The question is even more doubtful because some studies, analysing the association between smoking and tracheobronchial ACC, did not find any association, even though these anatomical sites are surely more exposed to the possible carcinogenic action of smoke than the major salivary glands ${ }^{18,19}$. With regard to alcohol consumption, an association with major salivary glands ACC was not found ${ }^{7,13}$. Miller et al. ${ }^{20}$ investigated the possible association of human papilloma virus (HPV) in sinonasal $\mathrm{ACC}$ and found that it is rare (11\%).

\section{Aetiology}

- Exposure to ionising radiation (atomic bomb survivors and patients treated with radiotherapy for a previous tumour, especially skin and childhood cancers).

- Low vitamin C intake.

- Women diagnosed with breast cancer have increased incidence of subsequent salivary gland cancer.

- In a case-control study, although not significant, the odds ratios for smoking among patients with ACC were above unity.

- An association between alcohol consumption and major salivary glands ACC was not found.

- The association of human papilloma virus (HPV) in sinonasal ACC is rare (11\%). 


\section{Epidemiology}

ACC arises mainly from the minor salivary glands and the submandibular gland, whereas it is uncommon in the parotid. The sites of origin in the head and neck are the tongue, paranasal sinuses, palate, nasopharynx, larynx, lacrimal glands and external auditory canal. ACC may also arise in secretory glands located in other tissues, such as in the tracheobronchial tree, oesophagus, breast, lungs, prostate, uterine cervix, Bartholin's glands and skin. In an historical study, Ranger et al. ${ }^{21}$ wrote that the hard and soft palate are the most involved sites in the oral cavity and that there are about 400 glands distributed over the hard and soft palates and the uvula.

Owing to the rarity of these tumours, there is little data on whether specific ethnic, geographic, or other factors predispose to development of the disease ${ }^{22}$. Concerning the distribution of ACC across the sites, there is no great difference between USA ${ }^{23}$ and Europe ${ }^{24}$, while there is an important difference in comparison with a Chinese study ${ }^{25}$, especially for oral cavity (30\% vs 7.5\%), major salivary glands (46\% vs 22\%), nasal cavity and paranasal sinuses (10\% vs $30 \%$ ), and lung and bronchus (4\% vs $24 \%$ ). $\mathrm{Mu}^{25}$ also reported a difference between an American cohort of 1,285 patients extracted from the Surveillance, Epidemiology and End Results (SEER) database and the Chinese cohort for age $<60$ years $(53.7 \%$ vs $75.4 \%)$. In the study by $\mathrm{Li}$ et al. ${ }^{23}$, patients with ACC of the eye and orbit were significantly younger at presentation than patients with ACC of the major salivary glands, while patients with tumours of the female genital system, skin and breast were significantly older. For all sites, except the lung and bronchus, more females than males were affected. The proportion of African Americans was significantly higher among patients with ACC of the female genital system or eye and orbit than among patients with ACC of major salivary glands. In the study by Spitz et al. ${ }^{7}$, the ethnic distribution of patients was white nonHispanic 86\%, black 9.4\% and Hispanic 4.6\%.

Salivary gland carcinomas are rare in children and adolescents and few large series have been published. In a series of 29 paediatric cases ${ }^{26}$ there were: 22 low-grade MEC, 4 acinic cell cancers, 1 ACC, 1 adenocarcinoma not otherwise specified and 1 sialoblastoma. In another series of 57 patients aged 20 years or younger ${ }^{27}$, the histologic types of the 38 carcinomas were MEC 19, acinic cell carcinoma 7, ACC 6 , secretory carcinoma (mammary analogue) 4 and myoepithelial carcinoma 2. Moreover, it is possible to find in the literature some case reports of unusual locations of ACC in childhood: an 8-year-old girl with ACC of the external auditory canal ${ }^{28}$, a 15 -year-old boy with ACC of the larynx ${ }^{29}$ and a 12-year-boy with ACC of the pyriform sinus ${ }^{30}$.

\section{Epidemiology}

- ACC arises mainly from the minor salivary glands of the head and neck (tongue, paranasal sinuses, palate, nasopharynx, larynx, lacrimal glands, and external auditory canal). It is common in the submandibular gland, whereas it is uncommon in the parotid.

- ACC may also arise in secretory glands located in other tissues, such as in the tracheobronchial tree, oesophagus, breast, lungs, prostate, uterine cervix, Bartholin's glands and skin.

- For all sites, except lung and bronchus, more females than males are affected by ACC. It is very rare in children and adolescents.

\section{Histopathology}

Salivary gland malignancies represent one of the most complex group of tumours from a pathological point of view. According to the World Health Organization (WHO) classifications (2005) ${ }^{31}, 24$ malignant histotypes are recognised, almost all characterised by specific morphological and genetic features as well as by particular clinical behaviour. The last WHO classification (2017) ${ }^{32}$ counts 23 malignant histotypes, No other site in the head and neck has such a large variety of malignant tumours. This variety as well as the rarity of some of them needs a skilled pathologist for diagnosis. Although ACC is one of the most common carcinomas of the salivary gland, in many pathology departments it is relatively uncommon, making it difficult for general pathologists to gain expertise in the field. Thus, the pathological diagnosis of ACC remains a challenge, especially in problematic cases. A study from 15 reference hospitals in Japan ${ }^{33}$ demonstrated that, after a central pathology review, the original diagnosis of ACC was changed to non-ACC in 21/219 cases (9.6\%). Moreover, 6 cases $(2.7 \%)$ were re-diagnosed as benign tumours; 3 of these patients had undergone useless postoperative radiotherapy. Both WHO classifications define ACC as a tumour that manifests a variety of tubular and cribriform structures with variably solid components. ACC has been traditionally subdivided into 3 histological groups (cribriform, tubular, and solid) based on solid components of the tumour ${ }^{34}$. Some studies have demonstrated that tumours with a solid growth component have a rapid fatal course, compared to tumours without a solid growth component ${ }^{34}$, but other studies have failed to correlate growth patterns with clinical course ${ }^{3}$. Moreover, no universally accepted grading system exists and no reproducibility studies of the existing grading systems have been performed. In fact, Therkildsen et al. examined the reproducibility of grading based on semi-quantitative assessment 
of the solid growth pattern in ACC. Two different grading systems were assessed by 3 observers on 59 ACC. Interobserver agreement was poor, except for the category "solid component constituting $50 \%$ or more of the tumour" 35 . In spite of its rarity, several studies have analysed molecular pathogenesis, genetic mutations and protein overexpression in ACC of the head and neck ${ }^{22,36,37}$. Recent whole genome and exome sequencing has dramatically improved our understanding of ACC pathogenesis. A balanced translocation resulting in the MYB-NFIB fusion gene appears to be a fundamental signature of ACC. In addition, sequencing has identified a number of other driver genes mutated in downstream pathways common to other well-studied cancers ${ }^{36}$. A study on 12 ACCs of the breast ${ }^{38}$, demonstrated that the mutational burden and mutational repertoire of breast ACCs are more similar to those of salivary gland ACCs than to other types of breast cancer.

\section{Histopathology}

- ACC is one of the most common carcinomas of the salivary gland, among 23 histotypes.

- Pathological diagnosis of ACC remains a challenge, especially in problematic cases.

- ACC has been traditionally subdivided into 3 histological groups (cribriform, tubular, and solid) based on solid components of the tumour, although no universally accepted grading system exists and no reproducibility studies of the existing grading systems have been performed.

- In spite of its rarity, several studies have analysed molecular pathogenesis, genetic mutations and protein overexpression in ACC of the head and neck.

\section{Clinical behaviour}

ACC is uncommon in the parotid gland. Its incidence in the historical large series presented by Eneroth ( 802 cases) ${ }^{39}$ and by Foote and Franzell (776 cases) ${ }^{4}$ lies between 2\% and 5\% of all tumours and between $6 \%$ and $15 \%$ of all malignancies. On the contrary, ACC is much more frequent in the submandibular gland. In 2 series studied by Spiro et al. ${ }^{40}$ and by Eneroth et al. ${ }^{41}$ the incidence of ACC was 42/121(35\%) and $25 / 62$ (40\%), respectively. It is difficult to define the incidence of ACC arising in the mucosal glands because of the heterogeneity of the series presented in many studied (major and minor salivary gland together). In an historic and weighty article, Osborn ${ }^{42}$ gathered the data from 21 major and minor series with a total of 1,712 mucosal gland malignant tumours of all types, of which 557 (32.5\%) were ACC. Osborn intro- duced the expression "cribriform adenocarcinoma, as being more appropriate to its origin, morphology, and behaviour". The signs and symptoms of ACC at presentation are not specific and depend on the anatomic site of involvement. Typically, a parotid ACC in the superficial lobe presents as a pre-auricular swelling, commonly less mobile than a pleomorphic adenoma because, even when it is circumscribed, it is unencapsulated. Deep lobe tumours are comparatively rare, given that the deep lobe accounts for only $10 \%$ to $20 \%$ of parotid tissue, and ACC is even more rare. In a study by Cohen et al. ${ }^{43}$, among 166 parapharyngeal space masses only $45(27.1 \%)$ were of salivary gland origin and only one was an ACC. Deep lobe tumours often present as an asymptomatic submucosal swelling of the lateral oropharyngeal wall and/or soft palate. Tumours presenting in the paranasal sinuses are associated with mild pain and pre-maxillary or palatal submucosal swelling with the overlying mucosa fixed to the tumour. The duration of these symptoms may range from months to several years. The slow growth and the absence or paucity of symptoms often result in delayed diagnosis and many patients present with advanced disease. Mainly for ACC, the late and soft symptoms may be a mild pain and paraesthesia, because "one of the most outstanding feature of this neoplasm, regardless of its site of origin, is its marked tendency to invade nerves. In our own surgical experience, invasion of the nerves is an almost constant microscopic finding. Although extension of neoplasm through nerves is not peculiar to the adenoid cystic carcinoma, this neoplasm certainly manifests this morbid finding more often than other epithelial neoplasms in the head and neck" ${ }^{44}$. Osborn ${ }^{42}$ wrote that this well-known characteristic feature of ACC was reported since 1934. The involved nerves may be the facial nerve for parotid tumours and the lingual nerve for submandibular location. For tumours in the paranasal sinuses or oral cavity, perineural spread is usually along the second and/or third branch of the trigeminal nerve. The foramens ovale and rotundum may be involved with extension of the tumour to the Gasserian ganglion ${ }^{44}$.

It is difficult to establish the real incidence of regional lymph node metastases from ACC because of the heterogeneity of the series presented in many studied (different sites of origin and all histologic types together). Regarding the parotid, Xiao et al. ${ }^{45}$ performed a thorough study on a series of 22,653 patients with parotid malignancy from the National Cancer Data Base (NCDB). Patients were considered to have positive nodal disease if there was at least one positive lymph node confirmed by biopsy or neck dissection as part of diagnosis or treatment or if they had clinical evidence of nodal disease during follow-up. The authors divided histologic types in low and high grade according to Seethala ${ }^{46}$. For ACC (2,045 cases, $9 \%$ of the series), the incidence of 
nodal metastases was $14.2 \%$ at presentation and $7 \%$ during follow-up (occult nodal disease). Interestingly, while for MEC, acinar cell carcinoma, salivary ductal carcinoma and adenocarcinoma not otherwise specified there was a great difference in the incidence of occult nodal disease between high and low grade, for ACC this difference was small (9.6\% vs 6.3\%). Regarding the paranasal sinuses, it is even more difficult to draw reliable data from the literature. Amit et al. ${ }^{47}$ reviewed 16 relevant articles, of which 13 presented very small series ( $\leq 35$ cases). The remaining 3 studies presented 64, 99 and 105 cases. Moreover, all studies included patients with tumours of both sinuses and the nasal cavity, and one study presented ACCs of the nasopharynx. The rate of node metastases at presentation ranged between $2 \%$ and $13 \%$. To the best of my knowledge, the only study dealing with tumours of the only paranasal sinuses and their regional metastases is that by Cantù et al. ${ }^{48}$. Among as many as 704 malignancies of the paranasal sinuses there were 115 ACCs (91in the maxillary sinus and 24 in the ethmoid sinus). Only 2 patients presented with node metastases, and only 3 patients developed regional metastases during follow-up, together with a relapse of the primary tumour.

ACC is generally recognised for its frequent and often silent distant metastases. They are rare at presentation, but at 10 years account for approximately $30 \%$ to $40 \%$. The commonest sites are lung, bone, liver and brain.

\section{Diagnostic workup}

In front of a parotid or submandibular gland swelling, after an anamnesis about the time of onset and speed of growth, accurate physical examination may help to distinguish an inflammatory disease from a tumour. It is advisable to look for possible skin scars on the scalp, face and external ear, as a result of resection of previous skin carcinoma or melanoma. Local pain at light palpation may be the symptom of an ACC, even in the absence of more advanced clinical indicators of malignancy (fixity to surrounding structures, nerves weakness or paralysis, presence of neck nodes). An ACC that develops in the minor salivary glands of the oral cavity almost always present as an asymptomatic submucosal mass, most commonly on the palate.

One must be careful of possible transformation into ACC of a recurrent pleomorphic adenoma after prior surgical resection. Among 106 patients with recurrent pleomorphic adenoma of the parotid gland, Yin et al. ${ }^{49}$ found $13(12.3 \%)$ patients with carcinoma, of which only $4 / 13(31 \%)$ had clinical features suspicious for malignancy. Toluie et al. ${ }^{50}$ analysed 89 cases of sinonasal ACC from the files of the Tumor Registry of the Armed Forces Institute of Pathology (AFIP) and found 9 cases with the presence of an antecedent or contemporaneous pleomorphic adenoma.

\section{Clinical behaviour}

- The incidence of ACC in the parotid gland is between $2 \%$ and 5\% of all tumours and between 6 and $15 \%$ of all malignancies. It is much more frequent in the submandibular gland (35\%-40\%). In a large study on mucosal gland malignant tumours of all types, $32 \%$ were ACC.

- Typically, a parotid ACC in the superficial lobe presents as a pre-auricular swelling, commonly less mobile than a pleomorphic adenoma. Deep lobe tumours often present as an asymptomatic submucosal swelling of the lateral oropharyngeal wall and/or soft palate. ACC of the submandibular gland presents as a swelling in the submandibular region.

- Those tumours located in the paranasal sinuses present as a pre-maxillary or palatal submucosal swelling with the overlying mucosa fixed to the tumour.

- One of the most outstanding feature of ACC, regardless of its site of origin, is its marked tendency to invade nerves. The involved nerves may be the facial nerve for parotid tumours and the lingual nerve for submandibular location. For tumours in the paranasal sinuses or oral cavity, perineural spread is usually along the second and/or third branch of the trigeminal nerve. The foramens ovale and rotundum may be involved with extension of the tumour to the Gasserian ganglion. Hence, the late and soft symptoms may be a mild pain and paresthesia and the duration of these symptoms may range from months to several years.

- Regional lymph node metastases from ACC of the parotid gland are rare (14.2\% at presentation and 7\% during follow up). The rate of node metastases from ACC of the paranasal sinuses at presentation ranged between $2 \%$ and $13 \%$.

- ACC is generally recognised for its frequent and often silent distant metastases. They are rare at presentation, but at 10 years they account for approximately $30 \%$ to $40 \%$. The commonest sites are lung, bone, liver and brain. 
Imaging

Radiological imaging is not mandatory for small, mobile and superficial parotid tumours. Ultrasound (US) examination with colour Doppler imaging has gained widespread acceptance as an economic, safe and useful method to detect and assess parotid gland masses. However, its diagnostic accuracy in distinguishing malignant from benign tumours does not reach a satisfactory diagnostic level ${ }^{51}$. Elastography is a relatively new way of tissue imaging associated with US. Some studies have found that malignant tumours are generally stiffer than benign ones. Shear wave elastography (SWE) is a novel elastographic method that offers the advantage of quantitative measurements and lower operator-dependence. It is well established in breast and thyroid gland lesions, but the results of elastography in salivary gland lesions have been rather poor so far ${ }^{52}$. Imaging with either CT or MRI is mandatory when there is the clinical suspicion of malignancy or when the lesion is thought to extend into or to arise from the deep lobe of the parotid gland or the parapharyngeal space. US examination or CT-MRI must be extended at least to the upper levels of the neck. MRI and/or CT is mandatory for sinonasal ACC and must be extended to the skull base. The patient must also undergo a chest CT.

\section{Fine-needle aspiration biopsy (FNAC) \\ and ultrasound-guided core biopsy (USCB)}

Studies on aspiration biopsy with large needles were performed as early as the $1930 \mathrm{~s}^{44}$, but the technique has not been accepted by most head and neck surgeons for the pos-

\section{Diagnostic work-up}

\section{Physical examination}

- In front of a parotid or submandibular gland swelling, after an anamnesis about the time of its onset and the speed of growing, an accurate physical examination may help to distinguish an inflammatory disease from a tumour. It is advisable to look for possible skin scars on the scalp, face and external ear, as result of resection of previous skin carcinoma or melanoma. Local pain at light palpation may be the symptom of an ACC, even in the absence of more advanced clinical indicators of malignancy. An ACC that develops in the minor salivary glands of the oral cavity almost always present as an asymptomatic submucosal mass, most commonly on the palate.

Imaging

- Radiological imaging is not mandatory for small, mobile, and superficial parotid tumours. Ultrasound (US) examination with colour Doppler imaging is an economic, safe and useful method to detect and assess parotid gland masses. However, its diagnostic accuracy in distinguishing malignant from benign tumours does not reach a satisfactory diagnostic level.

- Elastography is a relatively new way of tissue imaging associated with US. Some studies have found that malignant tumours are generally stiffer than benign ones.

- Imaging with either CT or MRI is mandatory when there is the clinical suspect of malignancy or when the lesion is felt to extend into or to arise from the deep lobe of the parotid gland or the parapharyngeal space. US examination or CT-MRI must be extended at least to the upper levels of the neck. MRI and/or CT are mandatory for sinonasal $\mathrm{ACC}$ and must be extended to the skull base. The patient must also undergo a chest CT.

Fine-needle aspiration biopsy (FNAC) and ultrasound-guided core biopsy (USCB)

- FNAC has become a commonly performed diagnostic test in the initial evaluation of a major salivary glands mass. The advantage of this technique is that it can be performed in the outpatient setting with low risk of complications. A potential disadvantage is that it has been associated with variable sensitivity and specificity in distinguishing malignant from benign disease and with variable rates of non-diagnostic and indeterminate cytology. FNAC has a low diagnostic potential for tumour typing and grading. The exact correlation between the primary cytological reports and the final histological diagnoses is about $63 \%$ and $71 \%$ respectively.

- USCB obtains a larger sample size for analysis than FNAC, which lowers the rate of sample inadequacy. However, the use of large bore needles in core biopsies has been associated with tumour seeding along the needle tract in some reports. 
sible risk of tumour dissemination or implantation. A series of Scandinavian studies on patients with long follow-up after aspiration biopsy and surgical removal of the tumour demonstrated no local recurrence ${ }^{53,54}$. Nowadays, FNAC has become a commonly performed diagnostic test in the initial evaluation of a major salivary glands mass. The advantage of this technique is that it can be performed in the outpatient setting with a low risk of complications. A potential disadvantage is that it has been associated with variable sensitivity and specificity in distinguishing malignant from benign disease and with variable rates of non-diagnostic and indeterminate cytology ${ }^{55-57}$. Liu et al. ${ }^{58}$ analysed 70 studies with as many as 6,784 FNAC. Among these, there were 518 non-diagnostic and 385 indeterminate results, constituting $13.3 \%$ of FNAC performed. The authors concluded that FNAC of the parotid gland has moderate sensitivity and high specificity in differentiating malignant from benign disease. However, FNAC has a low diagnostic potential for tumour typing and grading. Lindberg et al. ${ }^{59}$ and Zbaren et al. ${ }^{60}$ found that the exact correlation between primary cytological reports and final histological diagnoses was about $63 \%$ and $71 \%$, respectively. Frable et al. ${ }^{61}$ analysed several series of FNAC of salivary gland malignant tumours and found that the percentage of correct diagnosis for ACC was $66 \%$.

More recently, USCB has been increasingly used in preoperative workup of salivary glands . It is performed under ultrasound guidance after local anaesthesia with a 20-17 gauge needle ${ }^{62}$. Naturally, USCB obtains a larger sample size for analysis than FNAC, which lowers the rate of sample inadequacy. However, the use of large bore needles in core biopsies has been associated with tumour seeding along the needle tract in some reports ${ }^{63}$. Moreover, USCB is more expensive and timeconsuming than FNA. FNA combined with ultrasound imaging should continue to be the investigation method of first choice for salivary gland lesions, reserving USCB for those cases in which surgery is not suitable or after repeated failures of FNA to provide an adequate diagnosis ${ }^{64}$. Finally, Schmidt et al. ${ }^{65}$ conducted a systematic review of diagnostic test accuracy of 95 studies on needle biopsy (FNAC and USCB) of salivary gland lesions. They concluded that such studies overestimate the sensitivity and underestimate the specificity of FNAC. Moreover, studies on USCB had a lower rate of verification bias than FNAC studies and may have overestimated the advantage in diagnostic accuracy of USCB relative to FNA.

\section{References}

1 Ellington CL, Goodman M, Kono SA, et al. Adenoid cystic carcinoma of the head and neck: incidence and survival trends based on 1973-2007 surveillance, epidemiology, and end results data. Cancer 2012;118:4444-4451. https://doi.org/10.1002/cncr.27408

2 Stell PM. History of surgery of the upper jaw. In: Harrison D, Lund VJ, editors. Tumours of the upper jaw. Edinburgh: Churchill Livingstone; 1993. pp. 1-15.

3 Spiro RH, Huvos AG. Stage means more than grade in adenoid cystic carcinoma. Am J Surg 1992;164:623-628. https://doi.org/10.1016/ s0002-9610(05)80721-4

4 Foote Fw Jr, Frazell El. Tumors of the major salivary glands. Cancer 1953;6:1065-1133. https://doi.org/10.1002/10970142(195311)6:6<1065::aid-cncr2820060602>3.0.co;2-0

5 Saku T, Hayashi Y, Takahara O, et al. Salivary gland tumors among atomic bomb survivors, 1950-1987. Cancer 1997;79:1465-1475.

6 Boukheris H, Stovall M, Gilbert ES, et al. Risk of salivary gland cancer after childhood cancer: a report from the Childhood Cancer Survivor Study. Int J Radiat Oncol Biol Phys 2013;85:776-783. https://doi. org/10.1016/j.ijrobp.2012.06.006

7 Spitz MR, Tilley BC, Batsakis JG, et al. Risk factors for major salivary gland carcinoma. A case-comparison study. Cancer 1984;54:18541859. https://doi.org/10.1002/1097-0142(19841101)54:9<1854::aidcncr2820540915>3.0.co;2-1

8 Horn-Ross PL, Ljung BM, Morrow M. Environmental factors and the risk of salivary gland cancer. Epidemiology 1997;8:414-419. https:// doi.org/10.1097/00001648-199707000-00011

9 Swanson GM, Burns PB. Cancers of the salivary gland: workplace risks among women and men. Ann Epidemiol 1997;7:369-374. https://doi.org/10.1016/s1047-2797(97)00041-0

10 Horn-Ross PL, Morrow M, Ljung BM. Diet and the risk of salivary gland cancer. Am J Epidemiol 1997;146:171-176. https://doi. org/10.1093/oxfordjournals.aje.a009248

11 Falchook AD, Zevallos JP, Chera BS. Increased risk of salivary gland cancer among women with a previous cancer diagnosis. Head Neck 2016;38(Suppl 1):E446-451. https://doi.org/10.1002/hed.24016

12 Ewertz M, Mouridsen HT. Second cancer following cancer of the female breast in Denmark, 1943-80. Natl Cancer Inst Monogr 1985;68:325-329.

13 Sawabe M, Ito H, Takahara T, et al. Heterogeneous impact of smoking on major salivary gland cancer according to histopathological subtype: a case-control study. Cancer 2018;124:118-124. https://doi. org/10.1002/cncr.30957

14 Sadetzki S, Oberman B, Mandelzweig L, et al. Smoking and risk of parotid gland tumors: a nationwide case-control study. Cancer 2008;112:1974-1982. https://doi.org/10.1002/cncr.23393

15 Muscat JE, Wynder EL. A case/control study of risk factors for major salivary gland cancer. Otolaryngol Head Neck Surg 1998;118:195198. https://doi.org/0.1016/S0194-5998(98)80013-2

16 Hayes RB, Bravo-Otero E, Kleinman DV, et al. Tobacco and alcohol use and oral cancer in Puerto Rico. Cancer Causes Control 1999;10:27-33. https://doi.org/10.1023/a:1008876115797

17 Spitz MR, Fueger JJ, Goepfert H, et al. Salivary gland cancer. A case-control investigation of risk factors. Arch Otolaryngol Head Neck Surg 1990;116:1163-1166. https://doi.org/10.1001/ archotol.1990.01870100057012

18 Hsu AA, Tan EH, Takano AM. Lower respiratory tract adenoid cystic carcinoma: its management in the past decades. Clin Oncol (R Coll Radiol) 2015;27:732-740. https://doi.org/0.1016/j. clon.2015.06.012

19 Albers E, Lawrie T, Harrell JH, et al. Tracheobronchial adenoid 
cystic carcinoma: a clinicopathologic study of 14 cases. Chest 2004;125:1160-1165. https://doi.org/10.1378/chest.125.3.1160

20 Miller ED, Blakaj DM, Swanson BJ, et al. Sinonasal adenoid cystic carcinoma: Treatment outcomes and association with human papillomavirus. Head Neck 2017;39:1405-1411. https://doi.org/0.1002/ hed. 24778

21 Ranger D, Thackray AC, Lucas RB. Mucous gland tumours. Br J Cancer 1956;10:1-16. https://doi.org/10.1038/bjc.1956.1

22 Dillon PM, Chakraborty S, Moskaluk CA, et al. Adenoid cystic carcinoma: a review of recent advances, molecular targets, and clinical trials. Head Neck 2016;38:620-627. https://doi.org/10.1002/hed.23925

$23 \mathrm{Li} \mathrm{N}, \mathrm{Xu} \mathrm{L}$, Zhao H, et al. A comparison of the demographics, clinical features, and survival of patients with adenoid cystic carcinoma of major and minor salivary glands versus less common sites within the Surveillance, Epidemiology, and End Results registry. Cancer 2012;118:3945-3953. https://doi.org/10.1002/cncr.26740

24 Ciccolallo L, Licitra L, Cantú G, et al; EUROCARE Working Group. Survival from salivary glands adenoid cystic carcinoma in European populations. Oral Oncol 2009;45:669-674. https://doi.org/10.1016/j. oraloncology.2008.10.010

$25 \mathrm{Mu}$ X, Li Y, He L, et al. Prognostic nomogram for adenoid cystic carcinoma in different anatomic sites. Head Neck 2021;43:48-59. https:// doi.org/10.1002/hed.26443.

26 Locati LD, Collini P, Imbimbo M, et al. Immunohistochemical and molecular profile of salivary gland cancer in children. Pediatr Blood Cancer 2017;64(9). https://doi.org/10.1002/pbc.26468

$27 \mathrm{Xu} \mathrm{B}$, Aneja A, Ghossein R, et al. Salivary gland epithelial neoplasms in pediatric population: a single-institute experience with a focus on the histologic spectrum and clinical outcome. Hum Pathol 2017;67:37-44. https://doi.org/10.1016/j.humpath.2017.07.007

28 Zhou Q, Zhang H, Liu H. Adenoid cystic carcinoma of the external auditory canal associated with cholesteatoma in an 8-year-old girl. Int J Pediatr Otorhinolaryngol 2013;77:150-152. https://doi.org/10.1016/j. ijporl.2012.09.034

29 Liu W, Chen X. Adenoid cystic carcinoma of the larynx: a report of six cases with review of the literature. Acta Otolaryngol 2015;135:489493. https://doi.org/10.3109/00016489.2014.990583

30 De Campora E, Croce A, Bicciolo G, et al. Adenoid-cystic carcinoma (cylindroma) of the pyriform sinus in pediatric age. Int J Pediatr Otorhinolaryngol 1987;14:235-242. https://doi. org/10.1016/0165-5876(87)90036-x

31 Barnes L, Eveson JW, Reichart P, et al., editors. World Health Organization Classification of Tumours. Pathology and Genetics of Head and Neck Tumours. Lyon: IARC Press; 2005.

32 El-Naggar AK, Chan JKC, Grandis JR, et al., editors. WHO Classification of Head and Neck Tumours. $4^{\text {th }}$ ed. Lyon: IARC Press; 2017.

33 Ueda K, Murase T, Nagao T, et al. Central pathology review of salivary gland adenoid cystic carcinoma. Head Neck 2020;42:1721-1727. doi: 10.1002/hed.26081

34 da Cruz Perez DE, de Abreu Alves F, Nobuko Nishimoto I, et al. Prognostic factors in head and neck adenoid cystic carcinoma. Oral Oncol 2006;42:139-146. https://doi.org/10.1016/j.oraloncology.2005.06.024

35 Therkildsen MH, Reibel J, Schiødt T. Observer variability in histological malignancy grading of adenoid cystic carcinomas. APMIS 1997;105:559-565. https://doi.org/0.1111/j.1699-0463.1997. tb05053.x

36 Chae YK, Chung SY, Davis AA, et al. Adenoid cystic carcinoma: current therapy and potential therapeutic advances based on genomic profiling. Oncotarget 2015;6:37117-37134. https://doi.org/10.18632/ oncotarget.5076
37 Moskaluk CA. Adenoid cystic carcinoma: clinical and molecular features. Head Neck Pathol 2013;7:17-22. https://doi.org/10.1007/ s12105-013-0426-3

38 Martelotto LG, De Filippo MR, Ng CK, et al. Genomic landscape of adenoid cystic carcinoma of the breast. J Pathol 2015;237:179-189. https://doi.org/10.1002/path.4573

39 Eneroth CM. Histological and clinical aspects of parotid tumours. Acta Otolaryngol Suppl 1964;188(Suppl 191):1-99.

40 Spiro RH, Hajdu SI, Strong EW. Tumors of the submaxillary gland. Am J Surg 1976;132:463-468. https://doi. org/10.1016/0002-9610(76)90320-2

41 Eneroth CM, Hjertman L, Moberger G. Malignant tumours of the submandibular gland. Acta Otolaryngol 1967;64:514-536. https://doi. org/0.3109/00016486709139137

42 Osborn DA. Morphology and the natural history of cribriform adenocarcinoma (adenoid cystic carcinoma). J Clin Pathol 1977;30:195205. https://doi.org/0.1136/jcp.30.3.195

43 Cohen SM, Burkey BB, Netterville JL. Surgical management of parapharyngeal space masses. Head Neck 2005;27:669-675. https://doi. org/10.1002/hed.20199

44 Batsakis JG. Tumors of the Head and Neck. Clinical and pathological considerations. $2^{\text {nd }}$ Ed. Baltimore: Williams \& Wilkins; 1979.

45 Xiao CC, Zhan KY, White-Gilbertson SJ, et al. Predictors of nodal metastasis in parotid malignancies: a national cancer data base study of 22,653 patients. Otolaryngol Head Neck Surg 2016;154:121-130. https://doi.org/10.1177/0194599815607449

46 Seethala RR. An update on grading of salivary gland carcinomas. Head Neck Pathol 2009;3:69-77. https://doi.org/10.1007/ s12105-009-0102-9

47 Amit M, Binenbaum Y, Sharma K, et al. Adenoid cystic carcinoma of the nasal cavity and paranasal sinuses: a meta-analysis. J Neurol Surg B Skull Base 2013;74:118-125. https://doi.org/.1055/s-0033-1347358

48 Cantù G, Bimbi G, Miceli R, et al. Lymph node metastases in malignant tumors of the paranasal sinuses: prognostic value and treatment. Arch Otolaryngol Head Neck Surg 2008;134:170-177. https://doi. org/10.1001/archoto.2007.30

49 Yin LX, Van Abel KM, Rooker SA, et al. Risk factors for carcinoma ex pleomorphic adenoma in patients presenting with recurrence after resection of pleomorphic adenoma. Head Neck 2021;43:419-427. https://doi.org/10.1002/hed.26489

50 Toluie S, Thompson LD. Sinonasal tract adenoid cystic carcinoma expleomorphic adenoma: a clinicopathologic and immunophenotypic study of 9 cases combined with a comprehensive review of the literature. Head Neck Pathol 2012;6:409-421. https://doi.org/10.1007/ s12105-012-0381-4

51 Rzepakowska A, Osuch-Wójcikiewicz E, Sobol M, et al. The differential diagnosis of parotid gland tumors with high-resolution ultrasound in otolaryngological practice. Eur Arch Otorhinolaryngol 2017;274:3231-3240. https://doi.org/10.1007/s00405-017-4636-2

52 Heřman J, Sedláčková Z, Vachutka J, et al. Differential diagnosis of parotid gland tumors: role of shear wave elastography. Biomed Res Int 2017;2017:9234672. https://doi.org/10.1155/2017/9234672

53 Berge T, Soderstrom N. Fine-needle cytologic biopsy in diseases of the salivary glands. Acta Pathol Microbiol Scand 1963;58:1-9. https:// doi.org/10.1111/j.1699-0463.1963.tb04822.x

54 Zajicek J, Eneroth CM. Cytological diagnosis of salivary-gland carcinomata from aspiration biopsy smears. Acta Otolaryngol Suppl 1969;263:183-185. https://doi.org/10.3109/00016487009131551

55 Zbären P, Schär C, Hotz MA, et al. Value of fine-needle aspiration cytology of parotid gland masses. Laryngoscope 2001;111(11 Pt 1):1989-1992. https://doi.org/10.1097/00005537-200111000-00023 
56 Al-Khafaji BM, Nestok BR, Katz RL. Fine-needle aspiration of 154 parotid masses with histologic correlation: ten-year experience at the University of Texas M. D. Anderson Cancer Center. Cancer 1998;84:153-159.

57 Stewart CJ, MacKenzie K, McGarry GW et al. Fine-needle aspiration cytology of salivary gland: a review of 341 cases. Diagn Cytopathol 2000;22:139-146. https://doi.org/10.1002/ (sici)1097-0339(20000301)22:3<139::aid-dc2>3.0.co;2-a

58 Liu CC, Jethwa AR, Khariwala SS, et al. Sensitivity, specificity, and posttest probability of parotid fine-needle aspiration: a systematic review and meta-analysis. Otolaryngol Head Neck Surg 2016;154:9-23. https://doi.org/10.1177/0194599815607841

59 Lindberg LG, Akerman M. Aspiration cytology of salivary gland tumors: diagnostic experience from six years of routine laboratory work. Laryngoscope 1976;86:584-594. https://doi. org/10.1288/00005537-197604000-00016

60 Zbären P, Nuyens M, Loosli H, et al. Diagnostic accuracy of fine-needle aspiration cytology and frozen section in primary parotid carcinoma. Cancer 2004;100:1876-1883. https://doi.org/10.1002/cncr.20186
61 Frable MA, Frable WJ. Fine needle aspiration biopsy in the diagnosis of sarcoid of the head and neck. Acta Cytol 1984;28:175-177.

62 Zbären P, Triantafyllou A, Devaney KO, et al. Preoperative diagnostic of parotid gland neoplasms: fine-needle aspiration cytology or core needle biopsy? Eur Arch Otorhinolaryngol 2018;275:2609-2613. https://doi.org/10.1007/s00405-018-5131-0

63 Douville NJ, Bradford CR. Comparison of ultrasound-guided core biopsy versus fine-needle aspiration biopsy in the evaluation of salivary gland lesions. Head Neck 2013;35:1657-1661. https://doi. org/10.1002/hed.23193

64 Novoa E, Gürtler N, Arnoux A, et al. Diagnostic value of core needle biopsy and fine-needle aspiration in salivary gland lesions. Head Neck 2016;38 (Suppl 1):E346-352. https://doi.org/10.1002/hed.23999

65 Schmidt RL, Jedrzkiewicz JD, Allred RJ, et al. Verification bias in diagnostic accuracy studies for fine- and core needle biopsy of salivary gland lesions in otolaryngology journals: a systematic review and analysis. Head Neck 2014;36:1654-1661. https://doi.org/10.1002/ hed. 23495 